\title{
Dinámicas de transmisión de SARS-CoV-2: Transmisión oro-fecal
}

Dr. Daniel Ricardo Jiménez Corado ${ }^{1}$ Dra. María Fermanda Aquino Camey²

Fecha de recepción: 26/1/2021

Fecha de aceptación: 18/2/2021

\section{Resumen}

El objetivo de este artículo es proveer un repertorio de evidencia científica, que permita al lector conocer acerca de las diversas dinámicas de transmisión del coronavirus tipo 2, causante de síndrome respiratorio agudo severo (abreviado SARS-CoV-2 por sus siglas en inglés); tanto comprobadas como hipotéticas, en especial, la evidencia que sugiere la posible transmisión oro-fecal de este virus. EI SARS-CoV-2, es un virus altamente infeccioso que suele provocar, en su mayoría, una enfermedad asintomática o sintomática leve. La principal vía de transmisión de este virus es a través de gotas (de 5-10 micrometros de diámetro) que se expulsan a través de tos, estornudos, gritos, etc. Se ha detectado ARN de SARS-CoV-2 en diversas secreciones, fluidos y desechos corporales. A pesar de que se ha encontrado ARN de SARS-CoV-2 en heces de pacientes con la enfermedad, incluso algunos reportes refieren haber encontrado virus vivo, no se conoce aún si esto significa que el virus podría transmitirse por vía oro- fecal.

Palabras clave: coronavirus, SARS-CoV-2, dinámicas de transmisión, transmisión oro-fecal

\section{Transmission dynamics of SARS-CoV-2: Oro-fecal transmission}

\section{Abstract}

The objective of this article is to provide a repertoire of scientific evidence that allows the reader to learn about the various transmission dynamics of the severe acute respiratory syndrome type 2 coronavirus (SARS-CoV-2), both proven and hypothetical, especially the evidence suggesting the possible oro-fecal transmission of this virus. SARS-CoV-2 is a highly infectious virus that usually causes mostly asymptomatic or mild symptomatic disease. The main route of transmission of this virus is through droplets (5-10 micrometers in diameter) that are expelled through coughing, sneezing, shouting,

\footnotetext{
${ }^{1}$ Médico y cirujano, Magna Cum Laude, Universidad Rafael Landívar; investigador asociado del Instituto de Investigación y Estudios Superiores en Ciencias de la Salud (lecis).

${ }^{2}$ Médica y cirujana, Cum Laude, Universidad Rafael Landívar; investigadora asociada del Instituto de Investigación y Estudios Superiores en Ciencias de la Salud (lecis).
} 
etc. SARS-CoV-2 RNA has been detected in various secretions, fluids and body wastes. Although SARS-CoV-2 RNA has been found in feces of patients with the disease, including some reports of finding live virus, it is not yet known whether this means that the virus could be transmitted by the fecal-oral route.

Key words: coronavirus, SARS-CoV-2, transmission dynamics, oro-fecal transmission

\section{Introducción}

EI SARS-CoV-2 se ha diseminado rápidamente a nivel mundial entre los seres humanos, sin distinguir sexo, edad, nivel socioeconómico, religión o nacionalidad. Es el tercer coronavirus que ha causado una enfermedad severa de diseminación global en los últimos 20 años. EI SARS-CoV-2 pertenece a la familia Coronaviridae, es un virus envuelto, con genoma compuesto de ARN de hebra única con orientación positiva y no segmentado; posee espículas por lo cual su forma se asemeja a una corona solar. Este virus se caracteriza por presentar una alta capacidad de infectividad y por provocar una tasa elevada de personas contagiadas, asintomáticas o sintomáticas leves, por lo que favorece aún más su transmisión entre persona a persona. En la mayoría de los individuos inmunocompetentes, causa síntomas de resfriado común (1), (2), (3), (4).

\section{Vías de transmisión de SARS-CoV-2}

La principal vía de transmisión de SARS-CoV-2 es a través de gotas (de 5-10 micrometros) expulsadas durante interacción directa entre dos o más personas cuando tosen, estornudan, gritan o incluso cuando hablan. El riesgo se incrementa en forma directamente proporcional con el tiempo de interacción con una o más personas infectadas e inversamente proporcional con la distancia en la que se interactúa con la(s) persona(s) infectada(s), además, el riesgo incrementa si la persona con la que se interactúa se encuentra sintomática, lo que favorece cuantitativamente la excreción del virus (1), (2), (3), (5), (6).

Se han descrito otras formas de transmisión, entre ellas podemos encontrar las siguientes (1), (2), (3), (6):

a) Aerosoles: se definen como gotas pequeñas (menos de cinco micrometros de diámetro), usualmente quedan suspendidas en el aire por cierta cantidad de tiempo. Esta vía de transmisión es más importante en sitios sin ventilación y en servicios de salud, donde se realizan procedimientos médicos que son capaces de generar aerosoles.

b) Fómites: a pesar de que se ha demostrado que el virus sobrevive en superficies contaminadas por cierta cantidad de tiempo y que depende del tipo de superficie evaluada, no se ha demostrado la viabilidad de esta vía de transmisión.

c) Oro-fecal: Se ha demostrado presencia de ARN de SARS-CoV-2 en heces de pacientes con la infección, sin embargo, no se ha confirmado ningún caso que haya adquirido la enfermedad por esta vía. 
El rol del paciente asintomático y presintomático

El paciente asintomático es aquel paciente que, a pesar de estar contagiado, no presenta síntomas de la enfermedad; por su parte, el paciente presintomático, como su nombre lo indica, es el paciente que no ha desarrollado las manifestaciones características de la enfermedad. A pesar de no tener síntomas o no haberlos desarrollado aún, tanto el paciente asintomático como presintomático, tienen la capacidad de transmitir la enfermedad. Este tipo de pacientes, juegan un rol muy importante en la diseminación de algunas enfermedades infecciosas, incluso la causada por el SARS-CoV-2. Se sabe que la transmisión de SARS-CoV-2 mediada por estos pacientes contribuye significativamente a su diseminación, la cual puede suceder entre 1a 3 días antes que el paciente presintomático manifieste los primeros síntomas de la enfermedad (1), (6).

\section{Dinámicas de excreción} de SARS-CoV-2: Excreción en heces

Se ha detectado ARN de SARSCoV-2 en diversas secreciones, fluidos y desechos corporales como saliva, heces, orina, esputo, secreciones nasales, etc. Con respecto a la presencia de ARN de SARS-CoV-2 en heces, se han reportado diversos porcentajes de positividad en las muestras de pacientes con la enfermedad. Dichos porcentajes de positividad varían desde $0 \%$ hasta $100 \%$, pues depende del estudio que se tome en cuenta (2),(7). Incluso, se ha reportado la presencia de virus vivo en heces (8).
Implicación de la detección de SARS-CoV-2 en heces

La detección de SARS-CoV-2 en heces representa un hallazgo que puede modificar el curso del tamizaje, diagnóstico, prevención e incluso los criterios para determinar que un paciente ya no tiene la capacidad de transmitir el virus. Vale la pena aclarar que la presencia de ARN de SARS-CoV-2 en heces no lo hace automáticamente un virus que tenga la capacidad de transmitirse vía oro-fecal. A pesar que el receptor que utiliza el virus (receptor de la enzima convertidora de angiotensina II o ECA2) como parte de su proceso infeccioso, se encuentra en el tracto gastrointestinal, no se ha demostrado ningún caso que haya adquirido la enfermedad por esta vía. Cabe recalcar, que se ha reportado que la detección de ARN de SARS-CoV-2 en heces, puede persistir por varios días, incluso después de que ya no se detecte ARN del virus en las secreciones nasofaríngeas de algunos pacientes. Por último, cabe mencionar que no se ha demostrado una asociación entre detección del virus o su material genético en heces y la presencia de síntomas gastrointestinales o la severidad del cuadro clínico del paciente (8), (9), (10).

\section{¿Podría SARS-CoV-2 ser transmitido por vía oro-fecal?}

La transmisión oro-fecal de un patógeno, en su mayoría, se refiere a la excreción de este por las heces y la posterior contaminación de alimentos o agua con las mismas. En otros casos, se refiere a la excreción del patógeno por las heces, las cuales se concentran en aguas residuales y posteriormente formarse aerosoles a partir de las mismas, siendo una potencial fuente de transmisión. Es en esta última instancia, en donde el virus SARS-CoV-2, podría tener una potencial vía de transmisión (10).

El ejemplo más representativo de este mecanismo de transmisión se remonta al 2003 en Hong Kong, en donde se reportaron 342 casos y 42 muertes en habitantes de un edificio, quienes se contagiaron con SARSCoV-2. Según investigaciones realizadas en este caso, se cree que un sistema de plomería mal estructurado fue causa de la transmisión de dicho virus, ya que el mismo ingresó a los sistemas de drenaje y formó aerosoles luego de que se asentara en partículas fecales. Dichos aerosoles se diseminaron por medio de sistemas de ventilación y plomería dañada (2), (3), (10).

Actualmente, la única evidencia de posible transmisión orofecal de SARS-CoV-2, involucró un experimento realizado por Westhaus et al. (10), en donde una línea celular correspondiente a adenocarcinoma de colon fue incubada con muestras de aguas residuales purificadas y concentradas en donde se detectó ARN de SARS- CoV-2. Dicha línea celular se monitoreó por diez días en la búsqueda de 
un efecto citopático (indicativo de infección), sin embargo, no se encontró que hubiese algún cambio citopático en las células cultivadas con las muestras de aguas residuales en comparación con las células de control, que fueron cultivadas con una solución que contenía SARSCoV-2 viable, en e sí se observó un efecto citopático (11).

Aún quedan muchas preguntas por responder, falta comprender el cómo, cuándo y dónde puede ocurrir esta hipotética vía de transmisión de SARSCoV-2. Aunque no se tiene una respuesta definitiva con respecto a la posibilidad de que este virus tenga la capacidad de transmisión oro-fecal, es importante mantener todas las medidas de protección y bioseguridad recomendadas por las autoridades de salud, incluso el uso de mascarilla, lavado de manos y distanciamiento social. No obstante, cuando se tengan más respuestas, esto seguro impactará el sistema de salud y como se manejará esta enfermedad en el futuro desde la perspectiva de la prevención.

\section{Referencias}

6. Wiersinga W, Rhodes A, Cheng A, Peacock S, Prescott H. Pathophysiology, Transmission, Diagnosis, and Treatment of Coronavirus Disease 2019 (COVID-19). J JAMA. 2020;324(8):782. DOI: 10.1001 / jama.2020.12839.

7. Kitajima M, et al. SARS-CoV-2 in wastewater: State of the knowledge and research needs. S T Environment. 2020; 739, 139076. Disponible en: https:// doi.org/10.1016/j.scitotenv.2020.139076

8. Mandal P, Gupta A, Dubey B. A review on presence, survival, disinfection/ removal methods of coronavirus in wastewater and progress of wastewaterbased epidemiology. Jof El Chemical Engineering. 2020;8(5):104-317.

9. Gonzalez R, et al. COVID-19 surveillance in Southeastern Virginia using wastewater-based epidemiology. Wa Research. 2020;18(6):116-296.

Disponible en: https://doi.org/10.1016/j.watres.2020.116296

10. Langone $M$, et al. SARS-CoV-2 in water services: Presence and impacts. Environmental Pollution. 2021;(268):115-806. https://doi.org/10.1016/j. envpol.2020.115806

11. World Health Organization. Transmission of SARS-CoV-2: implications for infection prevention precautions. 2020. Disponible en: https://www.who.int/ news-room/commentaries/detail/transmission-of-sars-cov-2-implications-forinfection-prevention-precautions

12. Cheung K, et al. Gastrointestinal Manifestations of SARS-CoV-2 Infection and Virus Load in Fecal Samples From a Hong Kong Cohort: Systematic Review and Meta-analysis. Gastroenterology. N L of Medicine. 2020;159(1):81-95. https://doi.org/10.1053/j.gastro.2020.03.065

13. Cuicchi D, Lazzarotto T, Poggioli G. Fecal-oral transmission of SARS-CoV-2: review of laboratory-confirmed virus in gastrointestinal system. IntJ of Colorectal Dis. 2020. https://doi.org/10.1007/s00384-020-03785-7

14. Amirian E. Potential fecal transmission of SARS-CoV-2: Current evidence and implications for public health. Int J of Infec Dis. 2020;(95):363-370. https:// doi.org/10.1016/j.ijid.2020.04.057

15. Arslan M, Xu B, Gamal El-Din M. Transmission of SARS-CoV-2 via fecal-oral and aerosols-borne routes: Environmental dynamics and implications for wastewater management in underprivileged societies. Scie of The Total Envin. 2020;743:140709. https://doi.org/10.1016/j.scitotenv.2020.140709

16. Westhaus $\mathrm{S}$, et al. Detection of SARS-CoV-2 in raw and treated wastewater in Germany - Suitability for COVID-19 surveillance and potential transmission risks. ScieTotal Environt. 2021;7(51):141-750. https://doi.org/10.1016/j. scitotenv. 2020.141750 


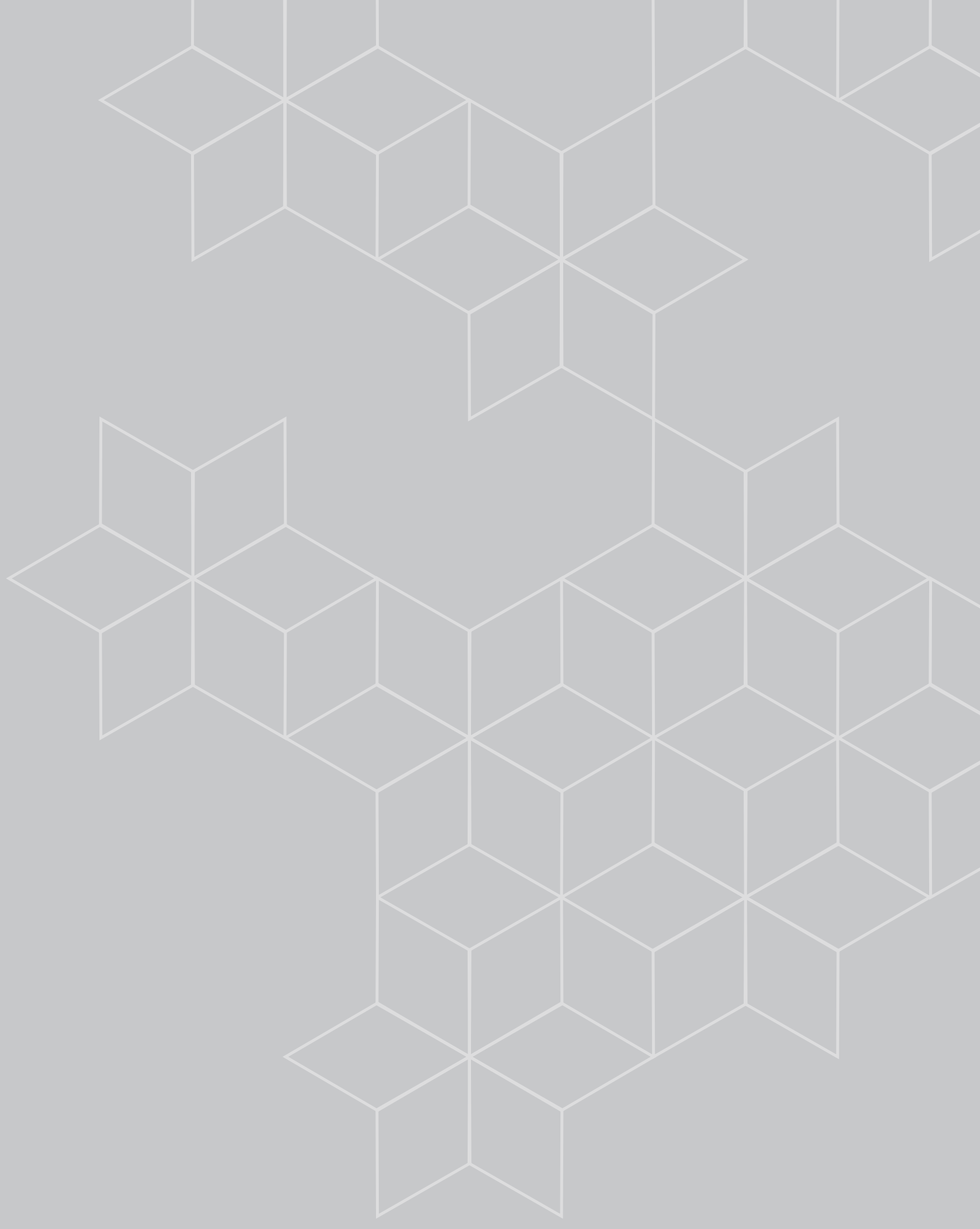

